\title{
UNUSUAL PRESENTATION OF SPLIT CORD MALFORMATION TYPE I ASSOCIATED WITH MYELOMENINGOCELA
}

\author{
Hakija BEČULIĆ ${ }^{1}$, Rasim SKOMORAC ${ }^{1}$, Aldin JUSIĆ ${ }^{1}$, Alma MEKIĆ-ABAZOVIĆ ${ }^{2}$ \\ Fahrudin ALIĆ ${ }^{1}$, Eldin BURAZEROVIĆ ${ }^{3}$, Alma VOLJEVICA ${ }^{4}$, Lejla BEČULIĆs
}

\author{
${ }^{1}$ Department of Neurosurgery, ${ }^{2}$ Department \\ of Oncology, Hematology and Radiotherapy \\ Cantonal Hospital Zenica, Zenica, Bosnia \\ and Herzegovina; ${ }^{3}$ Clinic of Neurosurgery \\ Clinical center University of Sarajevo \\ ${ }^{4}$ Institute of Anatomy, Faculty of Medicine \\ Sarajevo, Sarajevo, Bosnia and Herzegovina \\ ${ }^{5}$ Institute for Occupational and Sports \\ Medicine of Zenica-Doboj Canton, Zenica \\ Bosnia and Herzegovina \\ Corresponding author: \\ Hakija Bečulić \\ Department of Neurosurgery \\ Cantonal Hospital Zenica \\ 72000 Zenica \\ Bosnia and Herzegovina \\ dr_beculichakija@hotmail.com \\ Tel.: + 38732405133 \\ Fax.: + 38732405534 \\ Received: September 2, 2014 \\ Accepted: January 19, 2015 \\ Copyright (C) 2015 by \\ University Clinical Centre Tuzla. \\ E-mail for permission to publish: \\ paediatricstoday@ukctuzla.ba
}

Objective - We report an unusual case of split cord malformation (SCM) associated with open spinal dysraphism and other anomalies of the central nervous system. Case report - A male newborn was admitted to the Pediatric Intensive Care Unit immediately after birth by Caesarean delivery. Clinical examination and diagnostics (MRI) showed open spinal dysraphism in the distal part of the spine (level L5 and S1), split cord malformation type I which separated two hemicords, tethered cord and syringomyelia. Two days after birth microneurosurgery was performed. Cranial and cervical MRI showed Chiari I and corpus callosum hypoplasia. There was no hydrocephalus. Preoperatively the patient had paraparesis and discretely moved his left foot. MRI showed a dilated bladder so he may have had urinary retention. The postoperative recovery was satisfactory. The patient did not have any additional neurological deficit. The patient was followed up by a neurosurgeon, pediatric surgeon, pediatrician and physiatrist. Control MRI scans showed significant regression of the syrinx and some ascensus of the medulla. About 18 months after operation the patient had discrete paresis of the left foot. Conclusion - Complex spina bifida is an extremely rare condition. In this paper we describe this interesting case of complex spina bifida: a split cord malformation characterized by atypical bony morphology with a dural fold into the bone septum.

Key words: Unusual spinal dysraphism - Surgical treatment - Outcome.

\section{Introduction}

Split cord malformation (SCM) or diastematomyelia is a rare spinal anomaly and refers to a sagittal division of the spinal cord into two symmetrical or asymmetrical hemicords (1). SCM are of two types. Type I consists of two hemicords, each contained within its own dural sheath and separated by a median bony spur. Type II consists of two hemicords housed in a single dural tube separated by a fibrous median septum (2). In the absence of associated cutaneous stigmata that prompts the clinicians to request screening imaging for the spinal cord, SCM anomalies are usually diagnosed in relatively older children. Although their precise incidence is unknown, SCMs are rare abnormalities, representing $3.8 \%$ to $5 \%$ of all spinal cord anomalies (24). It is a form of occult spinal dysraphism, but it may coexist with open spinal dysraphism, such as meningomyelocele (complex spina bifida) (4). 
Open spina bifida or myelomeningocele (MMC) is a devastating congenital defect of the central nervous system. It is characterized by protrusion of the meninges and spinal cord through open vertebral arches (5). The incidence of myelomeningocele is about 1 per 1000 births. SCM may present with MMC (complex spina bifida) or without MMC as an occult anomaly. These anomalies are treated surgically. The goal of early surgical treatment is medula detethering, to prevent cerebrospinal fluid (CSF) leak and meningitis, as well as to prevent neurological deterioration in the future (3-6).

We report an unusual case of SCM associated with open spinal dysraphism and other anomalies of the central nervous system.

\section{Case report}

A male newborn was admitted to the Pediatric Intensive Care Unit immediately after birth by Caesarean delivery. Gestational age was 39 weeks. His APGAR score was 8 and 9 at 1 and $5 \mathrm{~min}$, his weight was 3470 grams, length $50 \mathrm{~cm}$, and head circumference 34.5 $\mathrm{cm}$. In the lumbosacral area an open spinal dysraphism (MMC) was detected. The patient was examined by a neurosurgeon who indicated Magnetic Resonace Imaging (MRI). MRI showed open spinal dysraphism (MMC) in the distal part of the spine with an arch defect at L5 and S1. SCM type I which separated two asymmetrical hemicords, tethered cord and syringomyelia (Fig. 1).

The conus medullaris was located at the level of inferior part of the S2 vertebra. The syrinx was located throughout the spinal cord. In the left hemicord it was $4.2 \times 3.7$ $\mathrm{mm}$, in the thoracal part $5.6 \times 8.1 \mathrm{~mm}$ and in the cervical part of the spinal cord there was discrete dilatation of the central canal. There were no other spinal anomalies. Two days after birth we performed microneurosurgery. General anesthesia was used. The patient was placed in the prone position with rolls under the chest and hips. In the lumbosacral area there was an MMC ( 40 x 35 mm) (Fig. 2).

We made an elliptical incision oriented vertically (along the axis of the MMC) just outside the normal skin. The incision was carried through the subcutaneous tissue to
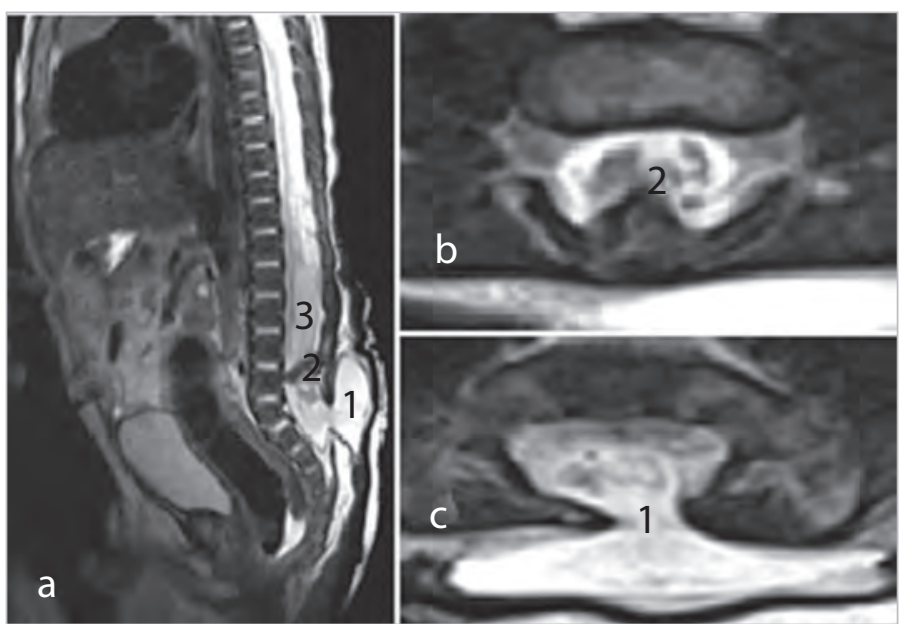

Fig. 1 Preoperative MRI of lumbosacral spine. (a) Sagittal T2 weighted - (1) an open spinal dysraphism in the distal part of the lumbosacral spine; (2) bone septum at the level of the L4 vertebra; (3) syringomyelia (b) Axial T2 weighted - (1) split cord malformation type I with two hemicords (c) Axial T2 weighted - (1) an open spinal dysraphism. 

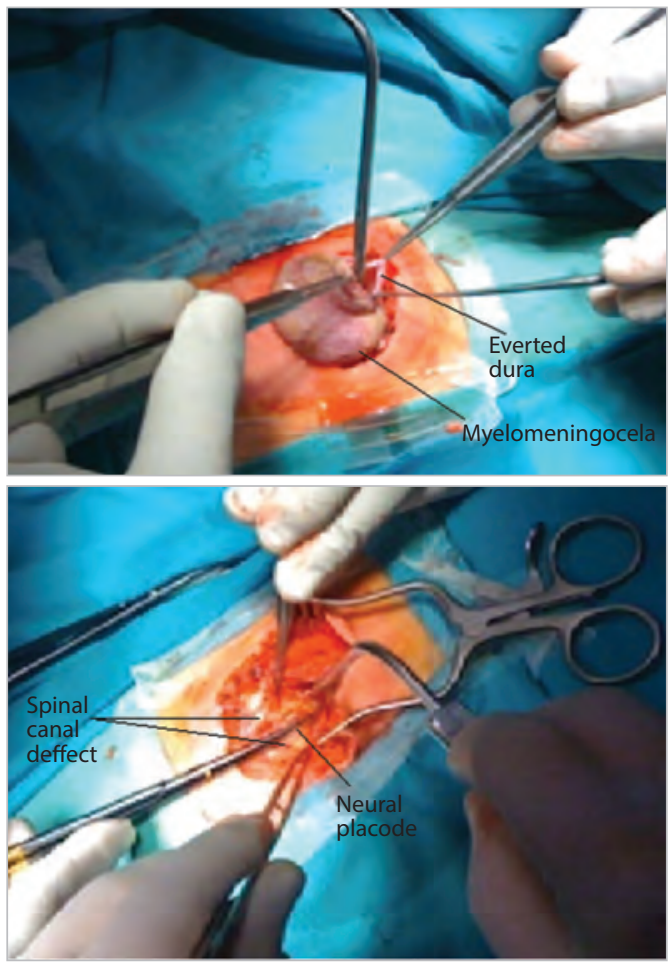

Fig. 2 Surgical repaire of myelomeningocele.

the layer of everted dura and fascial defect. We mobilized the base of the sac medially until the fascial defect was visible. The skin and the epithelium zone were excised around the neural placode. We reconstructed the neural placode and another part of the neural tissue and folded them into the tube. Then we closed the pia-arachnoidea junction and the dura was closed in a watertight manner using a 4/0 suture (Fig. 2). After this we made a vertical skin incision above the L3 and L4 vertebra and retracted the paraspinal muscles laterally. Carefully we made L4 laminotomy around the bone septum and exposing the dural cleft. Each hemicord had its own dural sheath. Using the dissector we detached the septum from the surrounding dura. Then we removed the superficial part of the bone septum using a ranger and showed another dural fold in the bone septum. The dural fold was a part of the right hemicord and entered in the bone septum at its base (Fig. 3).

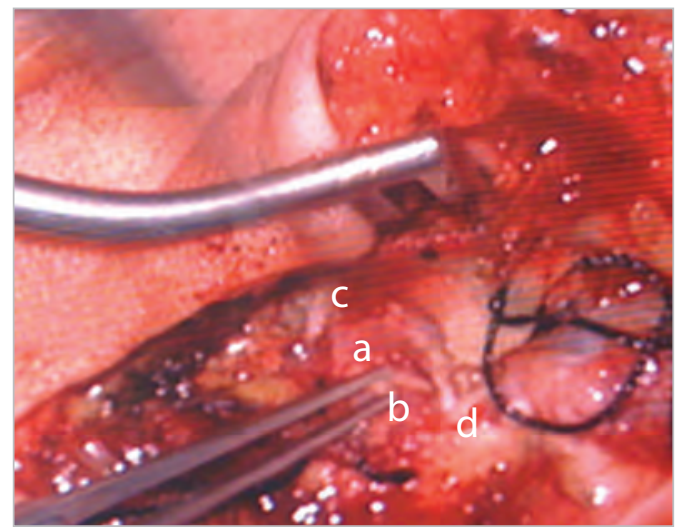

Fig. 3 An unusual split cord malformation. (a) Tubular osseous septum which spread along whole sagittal diameter of the spinal canal; (b) a dural fold into the osseous septum (which is part of the right hemicord); (c) the left hemicord; (d) the right hemicord, which is asymmetric.

We carefully removed the bony septum piece by piece from the vertebral body, Then fascia was closed as a separate layer using it laterally in a semicircle on both sides, elevating it from the underlying muscle and reflecting it medially. The fascia was closed with $4 / 0$ suture. The skin was mobilized by blunt dissection and closed. After the operation, the patient was readmitted to the Pediatric Intensive Care Unit. In the postoperative period we performed cervical and cranial MRI. There were no abnormalities in the cervical spine. Cranial MRI showed Chiari I and Corpus callosum hypoplasia (Fig. 4). There was no hydrocephalus. Additional diagnostic and abdominal echosonography did not show other anomalies.

The postoperative recovery was satisfactory. The patient did not have any additional neurological deficit. After surgery, we started early physical treatment. The patient was followed up by a neurosurgeon, pediatric surgeon, pediatrician and physiatrist. At the time of the latest check-up, the patient had discrete paresis of the left foot. Control MRI scans (one year after surgery) showed significant regression of the syrinx (in the left 


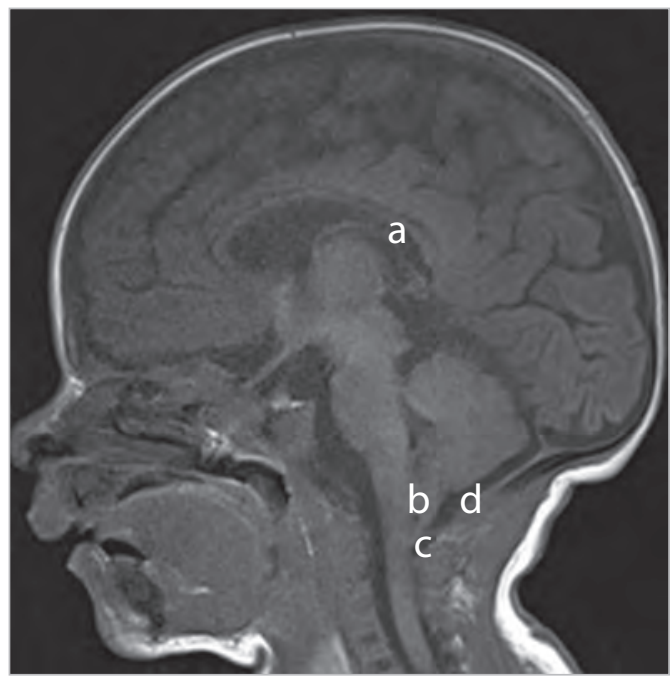

Fig. $4 M R I$ presentation of corpus callosum bypoplasia and Chiari I malformation (Sagital TI weighted): $a$-corpus callosum hypoplasia, b-tonsil descensus; $c-C 1$ vertebra, $d$-posterior rim of the foramen magnum.

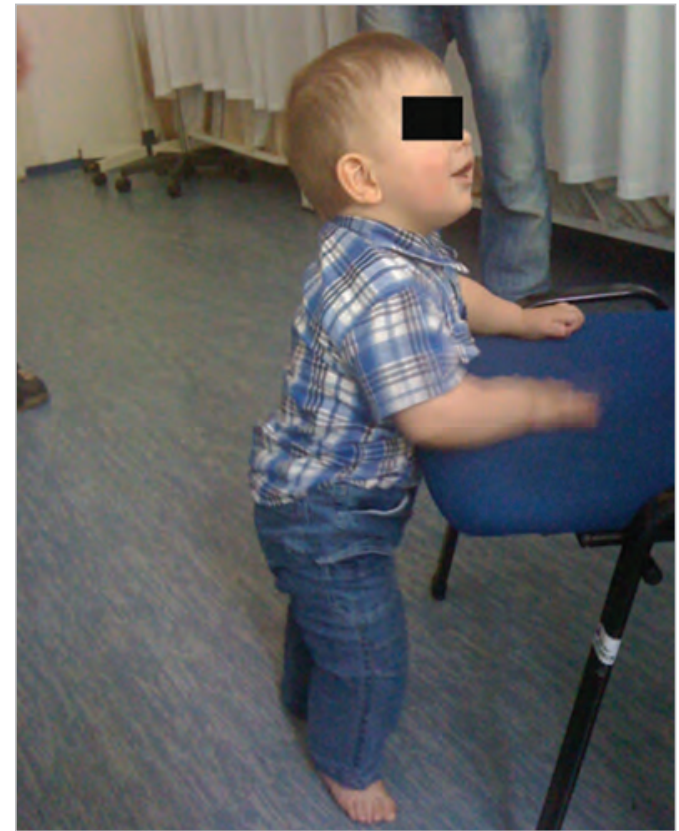

Fig. 6 The patient 18 months after surgery.
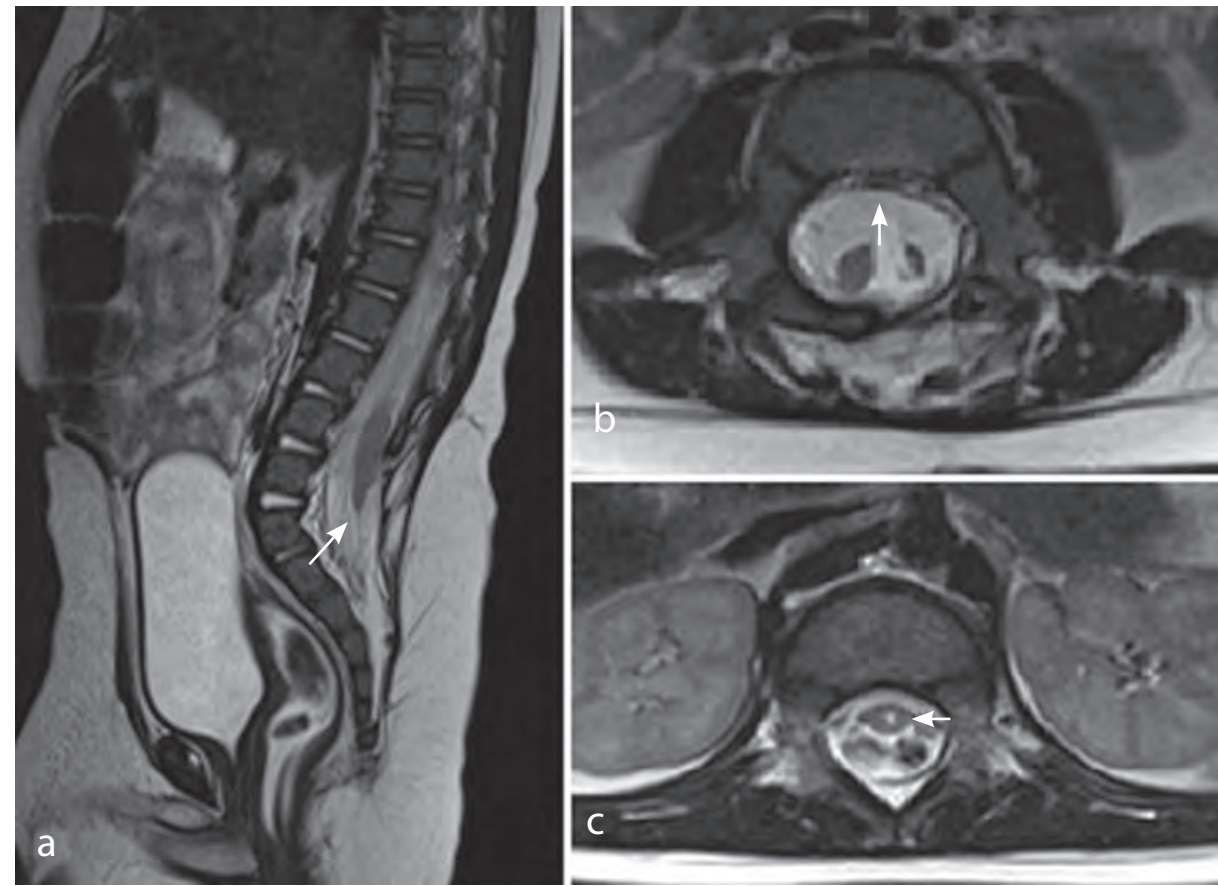

Fig. 5 Postoperative magnetic resonance imaging one year after surgery. (a) Sagittal T2 weighted - significant ascensus of the medulla without bone septum and myelomeningocele; (b) Axial T2 weighted - without any bone septum at the level of the L4 vertebra; (c) Axial T2 weightedsignificant regression of syringomyelia. 
hemicord $1.1 \times 1.2 \mathrm{~mm}$, in the thoracal part of medulla $3.2 \times 4.1 \mathrm{~mm}$, complete regression in the cervical part of the spinal cord) and some ascensus of the medulla (Fig. 5).

Now the boy is about 18 months old, walking with discrete paresis of the left foot (Fig. 6). Periodical check ups by echosonography have shown complete bladder emptying.

\section{Discussion}

Diastematomyelia was first described in 1837 by Olivier. The term is used to describe a developmental malformation of the spinal cord that is characterized by a splitting of the cord into at least two independent segments $(6,7)$. The term "Split cord malformation" (SCM) has been used since 1992 (7). SCM usually occurs in the lower thoracic or upper lumbar area $(6,7)$. Many hypotheses have been postulated for the genesis of these malformations. The most widely accepted theory about the embryogenesis of SCM was proposed by Pang et al. $(7,8)$. This theory is founded on the presence of an anomalous neuroenteric canal and maintains that the endomesenchymal tract causes all double cord malformations (7). SCM are of two types: type 1 consists of two hemicords, each contained within its own dural sheathed tube and separated by a median bony spur, and type 2 consists of two hemicords housed in a single dural tube separated by a fibrous median septum (4). SCM comprises 3.8\% of all spinal dysraphisms. SCM is known to be common among women. In two separate studies, the female: male ratio was reported as 1.3:1 (10). SCM may be accompanied by many congenital spinal disorders, such as low-lying cord, hydromyelia, lipoma, meningomyelocele, thick filum terminale and dermoid cysts $(6,9)$. The clinical presentations of split cord malformations can be classified as asymptomatic or symptomatic. Asymptomatic presentations are similar to those of other forms of occult spinal dysraphism. Symptomatic cases often present with progressive signs and symptoms. The most common presenting symptoms are scoliosis and tethered spinal cord syndrome $(4,5,9)$.

Myelomeningocele is a form of open neural tube defect and it is the most severe congenital malformation of the CNS compatible with survival (10). A myelomeningocele results from an abnormality in fusion of the embryologic neural tube during the first month of gestation. Failure of neural tube closure results in a sac-like herniation of the meninges (meningocele) or a herniation of neural elements (myelomeningocele). Adequate folic acid intake in the periconceptual and early pregnancy periods significantly reduces the risk of MMC (10-12). MMC most commonly occurs in the lumbosacral area. The average worldwide incidence of open spina bifida is 1 case per 1000 births (10). Neurological impairments caused by MMC include muscle weakness of the legs (paralysis), bowel and bladder dysfunction, seizures (cranial abnormalities, hydrocephalus), orthopedic abnormalities (feet and hip abnormalities, scoliosis) etc. $(11,12)$.

SCM is not merely an entity of occult dysraphism and it may coexist with open spinal dysraphism, such as MMC (complex spina bifida). About $40.8 \%$ cases of all SCM present with MMC, suggesting that the open and closed forms of spinal dysraphism may coexist (4).

The prognosis of SCM with MMC is not as good as in pure SCM cases. Progressive sensomotor deficit also has a higher incidence in cases of SCM with MMC $(3,4)$.

Chiari I and II malformations are associated with myelomeningocele (about 30\% cases), but not with SCM. Hydrocephalus has been more frequently observed in patients with SCM associated with MMC (26\%), than in those with pure SCM (11\%) $(4,13)$. Syrinx is seen in $25 \%$ to $40 \%$ of pa- 
tients with spinal dysraphism, and is more common in cases with both SCM and MMC $(13,15)$. Type I SCM consists of two hemicords separated by bone septum without the presence of other tissues (4).

In this paper we present a rare case of atypical SCM type I, associated with myelomeningocele and other CNS malformations (Chiari I, syringomyelia and tethered cord). In our case, the third dural fold passed into the bone septum. This dural fold belongs to the right hemicord. During microneurosurgery the bone septum was totally resected without any ventral dural deficit. The septum occurred at the caudal end of the split cord, leaving the more rostral aspect of the split free of attachments. Then myelomeningocela was repaired in the classical manner. In the postoperative period the patient did not have any additional neurological deficits. After surgery, we started early physical treatment. The patient was controlled by a neurosurgeon, pediatric surgeon, pediatrician and physiatrist. Control MRI scans showed significant regression of the syrinx and some ascensus of the medulla. Now the boy is aged about 18 months old, he is walking without paresis and without bowel and bladder control.

In the literature different variations of bone septum has been described: a double septum, a septum with dorsal or ventral insertion, a septum that separates the dural sac into three segments, a septum with bone and fibrous parts $(1,13-15)$. In the available literature we did not find a case with a dural fold passing into the bone septum.

\section{Conclusion}

Complex spina bifida is an extremely rare condition. MRI is a highly useful tool for determination of SCM and its accompanying spinal anomalies. In this paper we describe an interesting case of complex spina bifida: SCM characterized by atypical bone morphology with a dural fold into the bone septum. Early surgical management of the combined split cord malformation with myelomeningocele provides good results if managed adequately with removal of all tethering factors.

Authors' contributions: Conception and design: $\mathrm{HB}$ and $\mathrm{RS}$; Acquisition, analysis and interpretation of data: $\mathrm{HB}$ and $\mathrm{AJ}$; Drafting the article HB, AMA and FA; Revising it critically for important intellectual content: $\mathrm{HB}, \mathrm{EB}, \mathrm{AV}$ and LB.

Conflict of interest: The authors declare that they have no conflict of interest.

\section{References}

1. Moriya J, Kakeda S, Korogi Y, Soejima Y, Urasaki E, Yokota A. An unusual case of split cord malformation. AJNR. 2006; 27(7):1562-64.

2. Borkar SA, Mahapatra AK. Split cord malformations: A two years experience at AIIMS. Asian journal of neurosurgery. 2012;7(2):56.

3. Alzhrani GA, Al-Jehani HM, Melancon D. Multilevel Split Cord Malformation: Do We Need a New Classification? J Clin Imaging Sci. 2014;4:32.

4. Kumar R, Singh V, Singh SN. Split cord malformation (occult spina bifida): an Indian scenario. JK Science. 2005;7(4):192-4.

5. Mayer S, Weisser M, Till H, Grafe G, Geyer C. Congenital myelomeningocele-do we have to change our management. Cerebrospinal Fluid Res. 2010;7:17.

6. Banskota N, Jha R, Khadka N, Sharma GR, Bista P, Kumar P. Surgical Management of Spinal Dysraphism: Five -year Experience in a Central Hospital. J Nepal Paediatr Soc. 2014;34(1):34-3.

7. Pang D, Dias MS, Ahab-Barmada M. Split cord malformation part I: Unified theory of embryogenesis for double spinal cord malformation. Neurosurgery. 1992;31:451-60.

8. Mahapatra AK. Split cord malformation-A study of 300 cases at AIIMS 1990-2006. J Pediatr Neurosci. 2011;6:41-5.

9. Ozturk E, Sonmez G, Mutlu H, Sildiroglu HO, Velioglu M, Basekim CC, Kizilkaya E. Split-cord malformation and accompanying anomalies. J Neuroradiol. 2008;35(3):150-6. 
10. Piatt JH. Treatment of myelomeningocele: a review of outcomes and continuing neurosurgical considerations among adults: a review. J Neurosurg Pediatr. 2010;6(6):515-25.

11. Adzick NS, Thom EA, Spong CY, Brock JW, Burrow $\mathrm{PK}$, Johnson $\mathrm{M}$ et al. A randomized trial of prenatal versus postnatal repair of myelomeningocele. NEJM. 2011;364(11):993-1004.

12. Phillips BC, Gelsomino M, Pownall AL, Ocal E, Spencer HJ, O'Brien MS et al. Predictors of the need for cerebrospinal fluid diversion in patients with myelomeningocele. J Neurosurg Pediatr. 2014;14(2):167-72.

13. Patnaik A, Mahapatra AK. Complex forms of spinal dysraphism. Childs Nerv Syst. 2013;29(9):152732.

14. Akay KM, Izci Y, Baysefer A. Dorsal bony septum: A split cord malformation variant. Pediatr Neurosurg. 2002;36:225-8.

15. Chandra PS, Kamal R, Mahapatra AK. An unusual case of dorsally situated bony spur in a lumbar split cord malformation. Pediatr Neurosurg. 1999;31:49-52. 